\title{
Income and equity of access to physician services
}

\author{
Jeremiah Hurley, Michel Grignon
}

$\infty$

See related article page $\mathrm{I} 77$

$\mathrm{V}$ an Doorslaer and colleagues ${ }^{1}$ have produced a timely piece for Canadian health policy discussions regarding income, access to care and the role of private insurance. They examined equity in physician utilization in 2I member countries of the Organization for Economic Cooperation and Development (OECD), using data from nationally representative surveys conducted in 2000 or later. The analysis provides both good news and bad news for Canada. First the good news.

Absolute rates of physician visits in Canada, as measured by either the likelihood of any visit or the annual number of visits, are well within OECD norms. This conclusion would be reinforced if the observed rates were age-adjusted, since a number of European countries with high visit rates have greater proportions of elderly people in their populations than does Canada. ${ }^{2}$

Given absolute visit rates in Canada, the utilization profile for general practitioner services by income appears essentially to meet the test of horizontal equity: after standardizing for need, the likelihood of a visit to a general practitioner is slightly pro-rich, whereas the number of visits among those who have seen a doctor at least once is slightly pro-poor. Neither bias appears to have significance for health care policy.

The bad news is the more troubling findings with respect to the utilization of specialist services. The analysis reveals a pro-rich bias in needs-standardized utilization in Canada with respect to both the likelihood of a visit to a specialist and the number of specialist visits conditional on being a user. Why might such an income bias exist when physician services are free to all Canadians? The results of disease-specific studies confirm that the pro-rich bias is not due simply to differences across income groups in the underlying epidemiology of disease. Among Canadians with the same condition, those with higher incomes often have better access to specialized services. ${ }^{3-5}$ Rather, a number of both supply- and demandside factors may contribute, although at this stage one can only speculate on the relative contribution of each.

Potential supply-side factors include the geographic distribution of specialists and differences (conscious or unconscious) in provider behaviour toward patients of differing socioeconomic status. The distribution of specialists is more geographically unequal than is the distribution of general practitioners, with specialists particularly concentrated \& around academic health science centres. Academic health science centres tend to be located in relatively wealthy areas. Because use of services correlates highly with proximity to a provider, this may contribute to the pro-rich bias for specialist services. However, there is recent evidence that geographic and other supply-side measures contribute little to explaining income-related gradients in the use of angiograms, which casts doubt on whether such factors can be the primary determinants of the inequity. ${ }^{6}$ A growing body of literature also documents that physician treatment recommendations often differ by the income level, socioeconomic status and ethnicity of a patient..$^{7-12}$

\section{The results suggest that parallel private insurance will increase inequity of access to specialist services.}

Demand-side factors likely also play a role. Utilization of physician services depends in part on the demand for complementary services - for instance, the demand for prescription drugs. The demand for prescription drugs depends in part on drug insurance coverage. Because drug insurance in Canada is often linked to employment, higher-income Canadians are more likely to have drug insurance, which in turn induces them to utilize more physician services. Stabile, ${ }^{13}$ for instance, showed that having private drug insurance increased physician visit rates by $10 \%$ on average. Hence, private financing for many complementary health care services in Canada can exert an important influence on the utilization of publicly insured services. Higher-income patients, who also tend to be better educated, may be better able to navigate our supply-constrained system and be more effective in advocating for services. Systematic differences in attitudes may also exist across those with differing incomes: the very attitudes that led a higher-income person to invest more in education may also cause that person to invest more in his or her health, in part by using more health care services. It is interesting, for instance, that in their full analysis, ${ }^{14}$ van Doorslaer and colleagues found that education level is not associated with pro-rich inequity with respect to the probability of a specialist visit, but that it is significantly associated with the pro-rich inequity in the number of specialist visits. It is not possible to fully disentangle the demand- and supply-side forces, but such a finding is consistent with better-educated patients more effectively asserting their (greater) demand for specialist care.

The international comparison carries some potentially important lessons for health care policy debates in Canada. The most important is perhaps the link between equity of utilization and a country's system of financing. It should not be surprising that the 2 countries in the study that lack universal 
health care insurance coverage (Mexico and the United States) have both some of the lowest overall visit rates and the greatest income-related inequity of utilization. More subtle appears to be the effect of parallel private insurance (private insurance that covers publicly insured services) among those countries with universal public insurance coverage. Such private insurance is disproportionately purchased by the wealthy and is particularly targeted at specialist services. Countries in which parallel insurance plays an important role in financing (e.g., Ireland, Spain and Portugal) achieve equitable utilization of general practitioner services across income groups indeed, there is a tendency toward a pro-poor bias - but utilization for specialist services displays some of the highest degrees of inequity. The results of this study do not allow any definitive conclusions in this regard, but they caution against any illusion that parallel private insurance will increase access for anyone except the higher-income people who purchase it.

This study should provoke further, more detailed analyses of equity in Canada, using both the methods of van Doorslaer and colleagues and other methods. It would be interesting to know, for instance, how income-related equity varies across regions of Canada, and how equity may relate to factors other than income, such as distance from a provider or the size of community in which a person resides. Van Doorslaer and colleagues recognize that visits represent a relatively crude measure of utilization - what picture emerges when alternative measures are used, especially those that may incorporate aspects of quality? These and related forms of inequity must be documented as Canada's universal public insurance system is challenged in coming years.

From the Department of Economics, Centre for Health Economics and Policy Analysis (Hurley, Grignon), the Department of Clinical Epidemiology and Biostatistics (Hurley) and Gerontological Studies (Grignon), McMaster University, Hamilton, Ont.
Competing interests: None declared.

\section{REFERENCES}

I. van Doorslaer E, Masseria C, Koolman X; for the OECD Health Equity Research Group. Inequalities in access to medical care by income in developed countries. CMAJ 2006;174(2):177-83.

2. Organization for Economic Cooperation and Development (OECD). OECD Health Data 2005. Paris: The Organization; 2005.

3. Alter DA, Austin P, Tu JV. Effects of socio-economic status on access to invasive cardiac procedures and on mortality after acute myocardial infarction. $\mathrm{N} \mathrm{Engl} \mathrm{J}$ Med I999;34I(I8):1359-67.

4. Carrie AG, Metge CJ, Collins RM, et al. Predictors of receipt of flouroquinolone versus trimethosprim-sulfamethoxazole for treatment of acute pyelonephritis in women in Manitoba, Canada. Pharmacoepidem Drug Safe 2004;I3(I2):863-70.

5. Glazier RH, Creatore MI, Gozdyra P, et al. Geographic methods for understanding and responding to disparities in mammography use in Toronto, Canada. J Gen Int Med 2004;19(9):952-6r.

6. Alter D, Naylor C, Austin P, et al. Geography and service supply do not explain sociographic gradients in angiography use after mycardial infarction. CMAJ 2003; I68(3):26I-4.

7. Kikano GE, Schiaffino MA, Zyzanski SJ. Medical decision making and perceived socioeconomic slass. Arch Fam Med ig96; 5(267):270.

8. McKinlay JB, Potter DB, Feldman HA. Non-medical influences of medical decision making. Soc Sci Med I996;45(2):769-76.

9. O'Malley MS, Earp JA, Hawley MJ, et al. The association of race/ethnicity, socioeconomic status, and physician recommendations for mammography: Who gets the message about breast cancer screening? Am J Pub Health 200I;9I(I):49-54.

Io. Schulman KA, Berlin JA, Harless W. The effect of race and sex on physicians' recommendations for cardiac catheterization. N Engl J Med I999;340(8):618-26.

II. Solberg LI, Brekke ML, Kottke TE. Are physicians less likely to recommend preventive services to low-SES patients? Prevent Med 1997;26(350):357.

I2. Van Ryn M, Burke J. The effect of patient race and socioeconomic status on physicians' perceptions of patients. Soc Sci Med 2000;50(6):813-28.

I3. Stabile M. Private insurance subsidies and public health care markets: evidence from Canada. Can JEcon 200I;34(4):92I-42.

I4. Van Doorslaer E, Masseria C, OECD Health Equity Research Group. Income-related inequality in the use of medical care in 2I OECD countries. Paris: OECD, Health Working Paper No. I4; 2004.

Correspondence to: Dr. Jeremiah Hurley, Department of Economics and Centre for Health Economics and Policy Analysis, Kenneth Taylor Hall, Rm. 430, McMaster University, Hamilton ON L8S 4M4; fax: 905 52I-8232; hurley@mcmaster.ca

\section{ACCESS}

$C M A J$ is the only leading general medical journal that is free online. CMAJ.ca receives over 2 million hits per month of which two-thirds are from international readers. 